\title{
Alterações na Infilltração de Água em Latossolos Devidas à Incorporação Controlada de Resíduo Industrial de Silicatos
}

\section{EDISON AUGUSTO LUCIANO ${ }^{1} \&$ MÁRIO BENINCASA ${ }^{2}$}

\section{Depto de Física/ICGE/UNESP-Rua 10 no $2527-C E P$ 13500-230- CaixaPostal 178- Rio Claro/SP}

Fone/Fax: [55]-(0xx19) 526-2238 - e-mail: luciano@rc.unesp.br

${ }^{2}$ CEA/UNESP - Av. 24-A no 1515 - Bela Vista - CEP 13506-900 - Rio Claro/SP

Fone/Fax: [55]-(0xx19) 534-0122 - e-mail: cpggir@rc.unesp.br

\section{RESUMO}

No presente trabalho foram efetuados experimentos de infiltração de água em colunas de latossolos não saturados. Foram utilizados um Latossolo Vermelho Amarelo, um Latossolo Vermelho Escuro e um Latossolo Roxo, tratados com um resíduo de silicatos proveniente de uma indústria do município de Rio Claro, SP. O resíduo foi incorporado a cada solo em taxas de $1 \%, 2 \%, 5 \%$ e $10 \%$, em peso. Uma coluna de cada solo sem resíduo foi usada como controle. As posições da frente de molhamento em função da raiz quadrada do tempo de infiltração e as umidades iniciais e de saturação de cada coluna foram medidas. Os resultados mostraram que o aumento da concentração do resíduo incorporado, provocou a diminuição da velocidade da frente de molhamento. A principal conclusão é que a adição do resíduo diminuiu a infiltração da água nos solos, ao mesmo tempo em que aumentou a sua retenção, e isto é benéfico para a agricultura. Do ponto de vista ambiental, o aproveitamento do resíduo industrial como condicionador de solo também é benéfico, dentro dos limites do estudo, pois representa uma alternativa ao armazenamento do mesmo ou ao simples descarte em aterro sanitário.

PALAVRAS-CHAVE: resíduos sólidos industriais; silicatos; condicionadores de solo; infiltração de água em solo; retenção de água. 
In this work water infiltration experiments were carried out in horizontal unsaturated soils columns. Three soils, Red-Yellow Latosol, Dark-Red Latosol, and Dusky-Red Latosol were treated with a silicate residue produced by an industry from Rio Claro city, SP. The residue was added to each soil at the rate (in weight) of $1 \%, 2 \%, 5 \%$ and $10 \%$. A soil column without residue was used as a control. The position of wetting front as a function of the square root of the flow infiltration time, and water contents at air-dry and saturated soils columns were measured. The result shows that the increase on the rate of incorporated residue decreased the wetting front velocity. The main conclusion is that residue addition on soils decreased the water infiltration, whereas the water retention was increased, which is beneficial to the agriculture. From the environmental point of view, the use of the industrial residue as soil conditioner is beneficial within the limits of this study, since it represents an alternative to storage, and/or waste disposal.

KEY-WORDS: industrial solid residue; silicates; soil conditioner; soil water infiltration; water retention .

\section{INTRODUÇÃO}

Questões ambientais, relacionadas ao uso de materiais para produção de bens para atender às demandas da comunidades, já eram objeto de discussões na década de sessenta, geralmente associadas a movimentos políticos-sociais vigentes em países industrializados. O reconhecimento, entretanto, da gravidade destas questões, em âmbito mundial, verificou-se a partir do início da década de setenta, ao evidenciar a necessidade urgente de mudança de postura nas relações entre o homem e o meio ambiente e de equacionamento de dois problemas básicos e conseqüente busca de soluções: níveis de transformação das características do meio altamente comprometedoras da qualidade de vida, em geral e elevado risco de esgotamento de recursos naturais. Nesse contexto, aos benefícios gerados pela utilização de materiais, relaciona-se a necessidade das indústrias de transformação desenvolverem soluções apropriadas à destinação final de seus resíduos, o que via de regra exige estudos complexos.

Muitas indústrias, sensíveis à questão ambiental, tem se preocupado com a disposição final de seus resíduos e os tem tratado de forma a reduzir os impactos, reciclando parte deles ou reaproveitando-os para outros fins. Mesmo após seu tratamento e reciclagem, resulta ainda geração e acúmulo de grandes quantidades de resíduos que, na maioria das vezes, são poluentes. Normalmente são de difícil armazenagem e, comumente, esta é feita de forma inadequada.

O abandono de material não inerte, pode implicar na contaminação do solo e também do lençol freático. Se o material for inerte, ainda assim pode ocorrer o problema de sua lixiviação no solo, alterando as propriedades físicas do meio e influenciando diretamente o fluxo de água, a condutividade e difusividade hidráulica, e a porosidade do 
solo.

Entre vários exemplos análogos, que se poderia citar, destaca-se o problema que ocorre em indústrias de silicatos. Embora tendo preocupação com seus rejeitos e dispondo de sistemas de tratamento, elas geram volumes muito grandes de resíduos sólidos, trazendo como conseqüência a acumulação em áreas anexas.

Como esses materiais possuem um teor da ordem de $75 \%$ de óxido de silício $\left(\mathrm{S}_{\mathrm{i}} \mathrm{O}_{2}\right)$ na sua composição, várias propostas de solução têm sido sugeridas visando seu reaproveitamento na produção de novos materiais. Uma delas, seria sua incorporação em argilas cerâmicas para fabricação de pisos de alta resistência mecânica, como também a produção de vidros especiais, através de um tratamento térmico adequado. Uma outra possibilidade, é o estudo das conseqüências da incorporação desses rejeitos, como condicionadores ou corretivos para o solo.

A literatura é rica em estudos sobre os efeitos de materiais aplicados ao solo, de forma controlada, com o objetivo de lhe conferir benefícios de diferentes ordens: físicas, químicas ou biológicas (HICKMAN \& WHITNEY, s.d.; FREIRE \& MORETTI FILHO, 1979; SALATI et al., 1980; NIMAH et al., 1983; ÁVILA et al.,1988; GALBIATTI et al., 1991; GALBIATTI et al., 1992; BORGES et al., 1997 e AGGELIDES \& LONDRA, 2000). Na maioria dos casos são utilizados materiais orgânicos, de modo a se aproveitar os nutrientes contidos nos resíduos. Existem ainda alguns casos de materiais não orgânicos, que são utilizados para melhorar a retenção de água no solo.

No presente trabalho foi estudada a incorporação controlada, em três solos diferentes, de um resíduo gerado por indústria de silicatos, tendo como interesse mais imediato, conhecer o comportamento da infiltração de água nos solos na presença ou não do resíduo a eles incorporado em diferentes quantidades.

\section{TEORIA}

A infiltração, processo pelo qual a água penetra no solo, é de grande importância, pois determina o balanço de água na zona das raízes das plantas e, por isso, o conhecimento de seu mecanismo e de suas relações com as propriedades do solo, é fundamental para o manejo do solo e da água, especialmente em sistemas agrícolas. Um caso particular de infiltração é aquele no qual o efeito da gravidade pode ser desprezado, e é chamado de absorção.

Após um período de tempo de absorção numa coluna de solo uniforme, a distribuição da umidade ao longo da coluna pode ser caracterizada por diferentes zonas: 
zona saturada, zona de transição, zona de transmissão, zona de molhamento e frente de molhamento, que é o limite visível da penetração da água, apresentando um gradiente de pressão muito grande, principalmente nos solos inicialmente secos.

A adição de condicionadores ao solo provoca alterações em suas propriedades físicas, as quais podem ser identificadas e estimadas através de um estudo da infiltração.

Para o presente estudo de efeitos da incorporação de resíduo ao solo, foi escolhido como indicador das alterações nas propriedades físicas, um método experimental de absorção de água em colunas horizontais de solo, de modo a não se considerar o efeito da gravidade.

O método utilizado é o de Bruce e Klute, descrito por REICHARDT et al. (1975) onde uma coluna horizontal de solo, uniforme, de secção transversal constante, com densidade global também constante, de comprimento semi-infinito, tendo uma umidade volumétrica inicial constante $\theta_{0}$, é submetida à infiltração. A superfície de uma das extremidades da coluna é mantida a uma umidade volumétrica constante $\theta_{1}$ por todo o tempo da absorção, enquanto a outra é fechada por uma peneira, para permitir a saída de ar. A água penetra então no solo e a umidade volumétrica $\theta$ será uma função da posição $x$ e do tempo $t$.

O movimento unidimensional de água no solo não saturado, contido na coluna, pode ser descrito pela equação de difusão,

$$
\frac{\partial \mathscr{\partial}}{\partial t}=\frac{\partial}{\partial x}\left[D(\partial) \frac{\partial \mathscr{\partial}}{\partial x}\right]
$$

onde $\theta=\theta(x, t)$ é a umidade volumétrica, em $\mathrm{cm}^{3} / \mathrm{cm}^{3}, \mathrm{D}(\theta)$ é a difusividade da água no solo, em $\mathrm{cm}^{2} / \min$, e $x$ e $t$ são as coordenadas de posição e tempo, respectivamente.

Esta equação está sujeita à condição inicial e às condições de contorno:

$$
\begin{gathered}
\theta=\theta_{0} \text { para qualquer } x>0 \text { em } t=0 \\
\theta_{=} \theta_{1} \text { para } x=0 \text { em qualquer } t>0(2)
\end{gathered}
$$


$\theta=\theta_{0}$ para $x$ além de $x_{f} ;(x \rightarrow \infty)$, em qualquer $t>0$

A equação (1) é uma equação diferencial a derivadas parciais, não linear, e, através da transformação de Boltzmann,

$$
\phi(x, t)=x t^{-1 / 2}(3)
$$

é possível torná-la uma equação diferencial ordinária.

Assim, a umidade $\theta(x, t)$ que era uma função de duas variáveis, fica dependendo apenas de uma variável $\phi, \theta(x, t)=\theta(\phi)$.

A equação (3) permite explicitar uma solução particular da equação (1), sujeita às condições (2), que é

$$
x(\theta, t)=\phi(\theta) t^{1 / 2}
$$

onde agora $x$, e não $\theta$, é a variável dependente.

Observando agora a posição da frente de molhamento $x_{f}$, tem-se que para cada solo, ela é uma função de $\phi(\theta)$ e conseqüentemente de sua umidade característica $\theta$, e de $t^{1 / 2}$, dada pela equação (4). Assim,

$$
x_{f}(\theta, t)=f(\theta) t^{1 / 2}
$$

A validade deste modelo é testada medindo-se então a posição da frente de molhamento $x_{f}$ a partir da extremidade da coluna, em função da raiz quadrada do tempo, $t^{1 / 2}$. Como resultado, deve-se obter uma reta que passa pela origem; caso contrário, não é possível usar este modelo para o solo estudado. No caso do gráfico ser de fato uma reta que passa pela origem, observa-se que $\theta$ tem um valor constante para o solo em estudo, na umidade da frente de molhamento, que é justamente o valor do coeficiente angular da reta obtida. Este valor indica a velocidade do movimento da água naquele solo.

Fazendo então os gráficos de $x_{f}$ em função de $t^{1 / 2}$ para cada concentração de resíduo incorporada ao solo, o coeficiente angular de cada reta obtida dará o valor da velocidade do escoamento naquela concentração. 
Foram utilizadas para esta pesquisa amostras de terra de três solos distintos: Latossolo Vermelho Amarelo - solo residual amarelo avermelhado, arenoso - coletado no bairro Mãe Preta em Rio Claro-SP; Latossolo Vermelho Escuro - solo residual e coluvionar, argiloso, marrom escuro a avermelhado - coletado no Centro de Estudos Ambientais da Unesp / Câmpus da Bela Vista, em Rio Claro-SP e Latossolo Roxo eutrófico, textura muito argilosa, marrom avermelhado, coletado na Faculdade de Ciências Agrárias e Veterinárias da Unesp / Câmpus de Jaboticabal-SP, que serão designados por LVA, LVE e LR, respectivamente.

Utilizou-se também um resíduo sólido, obtido junto a uma indústria de silicatos do município de Rio Claro-SP. A composição do resíduo é dada na Tabela 1.

Tabela 1: Dados médios de análise por Raio-X do resíduo, em porcentagem (\%).

\begin{tabular}{|c|c|c|c|c|c|c|c|c|c|c|}
\hline $\mathrm{SiO}_{2}$ & $\mathrm{TiO}_{2}$ & $\mathrm{Al}_{2} \mathrm{O}_{3}$ & $\mathrm{Fe}_{2} \mathrm{O}_{3}$ & MnO & $\underset{\%}{\mathrm{MgO}}$ & $\mathrm{CaO}$ & $\mathrm{Na}_{2} \mathrm{O}$ & $\mathrm{K}_{2} \mathrm{O}$ & $\mathrm{P}_{2} \mathrm{O}_{5}$ & LOI \\
\hline 74,75 & 0,09 & 0,63 & 0,71 & 0,01 & 1,15 & 8,13 & 2,32 & 0,06 & 0,04 & 11,83 \\
\hline
\end{tabular}

Os solos e o resíduo foram deixados secar ao ar, por vários dias e, em seguida foram passados em peneira com malha de $1 \mathrm{~mm}$.

Para o procedimento experimental de infiltração de água em solos, foram utilizadas colunas de acrílico de $40 \mathrm{~cm}$ de comprimento e 5,3 cm de diâmetro interno com um volume de trabalho medido de $725 \mathrm{~cm}^{3}$.

Para cada solo foi misturada uma quantidade de resíduo nas concentrações $1 \%, 2 \%, 5 \%$ e $10 \%$ em peso, de acordo com a Tabela 2 .

Tabela 2: Massas dos solos $\left(\mathrm{m}_{1}, \mathrm{~m}_{2}, \mathrm{~m}_{3} ; \mathrm{g}\right)$ e de resíduo $\left(m_{r} ; \mathrm{g}\right)$ que foram misturadas para o preparo das colunas, valores das massas de cada mistura $\left(m_{m} ; \mathrm{g}\right)$ e valores das densidades de cada mistura $\left(\rho_{m} ;\right.$ g.cm $\left.{ }^{-3}\right)$.

\begin{tabular}{|c|c|c|c|c|}
\hline solo puro & & resíduo & incorporado & \\
\hline (testemunhas) & $1 \%$ & $2 \%$ & $5 \%$ & $10 \%$ \\
\hline
\end{tabular}




\begin{tabular}{|c|c|c|c|c|c|}
\hline \multicolumn{6}{|c|}{ LVA } \\
\hline $\mathbf{m}_{1}$ & 1107,00 & 1079,53 & 1053,39 & 982,04 & 882,44 \\
\hline$m_{r}$ & 0 & 10,80 & 21,07 & 49,10 & 88,24 \\
\hline$m_{m}$ & 0 & 1090,32 & 1074,45 & 1031,15 & 970,68 \\
\hline$\rho_{m}$ & 1,53 & 1,50 & 1,48 & 1,42 & 1,34 \\
\hline \multicolumn{6}{|c|}{ LVE } \\
\hline $\mathbf{m}_{2}$ & 910,00 & 891,35 & 873,46 & 823,83 & 752,57 \\
\hline$m_{r}$ & 0 & 8,91 & 17,47 & 41,19 & 75,26 \\
\hline$m_{m}$ & 0 & 900,27 & 890,92 & 865,02 & 827,82 \\
\hline$\rho_{m}$ & 1,26 & 1,24 & 1,23 & 1,19 & 1,14 \\
\hline \multicolumn{6}{|c|}{ LR } \\
\hline $\mathbf{m}_{3}$ & 1050,00 & 1025,25 & 1001,64 & 936,92 & 845,83 \\
\hline$m_{r}$ & 0 & 10,25 & 20,04 & 46,85 & 84,58 \\
\hline$m_{m}$ & 0 & 1035,51 & 1021,68 & 983,77 & 930,42 \\
\hline$\rho_{m}$ & 1,45 & 1,43 & 1,41 & 1,36 & 1,28 \\
\hline
\end{tabular}

Foram então preparadas as colunas com as misturas solo-resíduo, além de colunas com os solos testemunhas. As misturas e os solos foram compactados nas colunas batendo-se com um bastão de madeira na parede da coluna, buscando obter uma compactação uniforme e semelhante para todos.

Cada coluna foi montada de acordo com um arranjo experimental onde uma das suas extremidades é fechada com uma tela metálica e com um papel de filtro entre ela e o solo. Essa extremidade está conectada através de uma válvula a um reservatório de água (reservatório de Mariotte - para manutenção de pressão constante) a uma pressão negativa de $5,0 \mathrm{~cm}$ de coluna de água a partir do centro da coluna. $\mathrm{Na}$ outra extremidade existe apenas uma tela metálica, que sustenta o solo, mas não impede a saída livre de ar. 
Inicialmente a válvula que conecta o reservatório à extremidade da coluna está fechada. Uma vez aberta essa válvula, inicia-se a cronometragem da infiltração de água, e através de uma régua fixada ao logo da coluna, com o zero coincidindo com a extremidade onde entra a água, mede-se a posição da frente de molhamento, a cada intervalo de tempo medido pelo cronômetro. Foi medido então um conjunto de dados $x_{f} \mathrm{e}$ $t$.

Desta forma foram efetuadas medidas para cada amostra de solo testemunha e para cada amostra de mistura, num total de 15 amostras. Foram feitas cinco repetições para cada coluna, para efeito de análise estatística, perfazendo assim 75 amostras.

Foram medidas também, para cada coluna, a umidade inicial ou residual da amostra seca ao ar, $\theta_{0}$, e a umidade de saturação, $\theta_{1}$. De cada coluna foi retirada uma quantidade seca ao ar e uma saturada, sendo essas quantidades pesadas em balança analítica, com precisão de $0,01 \mathrm{~g}$. Em seguida, essas amostras foram secas em estufa, por 24 horas, a uma temperatura média de $105^{\circ} \mathrm{C}$, e novamente pesadas.

As umidades são dadas pelas relações

$$
\begin{aligned}
& \theta_{0}=\left[\left(m_{0}-m\right) / m\right] \rho(6) \\
& \theta_{1}=\left[\left(m_{1}-m\right) / m\right] \rho(7)
\end{aligned}
$$

onde $m_{0}$ é a massa da amostra seca ao ar, $m_{1}$ é a massa da amostra saturada, $m$ é a massa da amostra seca na estufa, e $\rho$ é a densidade da amostra.

Todas as medidas foram efetuadas em laboratório, em dias sem chuva, com a umidade relativa do ar, média, entre $60 \%$ e $70 \%$, e com uma temperatura média entre $22^{\circ} \mathrm{C}$ e $26^{\circ} \mathrm{C}$, medidas no interior do laboratório.

\section{RESULTADOS E CONCLUSÕES}

Com os dados medidos da posição da frente de molhamento, foram traçadas curvas de $x_{f}$ em função de $t^{1 / 2}$ para cada solo e suas respectivas misturas solo-resíduo. Todas as curvas apresentaram uma tendência linear, em concordância com a equação (5) do modelo teórico, possibilitando assim a utilização do mesmo. Foi feita então uma regressão linear e traçada a melhor reta para cada uma das curvas.

As curvas para cada um dos solos LVA, LVE e LR, e suas diversas 
concentrações de resíduo, estão apresentadas nas Figuras 1, 2 e 3, respectivamente. Cada curva de um gráfico mostra o comportamento de cada uma das misturas estudadas.

$\mathrm{Na}$ Tabela 3 são apresentados os valores das umidades inicial ou residual ( $\theta$ $\left.0^{)}\right)$de saturação $\left(\theta_{1}\right)$ e dos parâmetros das retas de regressão linear $\left(\mathbf{m}_{\mathbf{i}}, \mathbf{R}, \mathbf{R}^{\mathbf{2}}\right)$ das curvas dos gráficos das Figuras 1, 2 e 3. Para maior facilidade de análise, essas retas estão colocadas em mesmo gráfico (Figura 4).

Os resultados obtidos estão perfeitamente de acordo com o esperado pelo modelo teórico utilizado. Os valores dos coeficientes angulares das retas apresentados na Tabela 3 são os valores constantes da função $\phi(\theta)$ da Equação (5), na posição da frente de molhamento.

Analisando as retas de cada solo puro da Figura 4, linha negra superior de cada solo, observa-se que o LVA apresenta uma reta com inclinação maior que a do LVE, e este, uma reta com inclinação maior que a do LR, indicando, nesta ordem, uma menor velocidade do escoamento de água, segundo o modelo teórico. Isto se deve ao fato do solo LVA ser mais arenoso que o LVE e do LR ser mais argiloso que o LVE. Analisando agora cada solo individualmente, através da Figura 4, ou das Figuras 1, 2 e 3, verifica-se que a inclinação de suas retas diminui e, portanto, diminui a velocidade do escoamento de água, quando se aumenta a incorporação de resíduo ao solo, até os limites considerados. Verifica-se que esse comportamento é comum aos três solos estudados.

O aumento na concentração de resíduo no LVA, leva a uma diminuição da inclinação das retas, levando este solo a apresentar um comportamento hídrico parecido ao do LVE. O mesmo ocorre com o LVE, quando é aumentada a concentração de resíduo; o seu comportamento hídrico tende para o do LR. Mesmo o LR, que já possui uma velocidade de escoamento menor que os outros dois, também tem sua velocidade de escoamento bastante afetada pela adição de resíduo. 


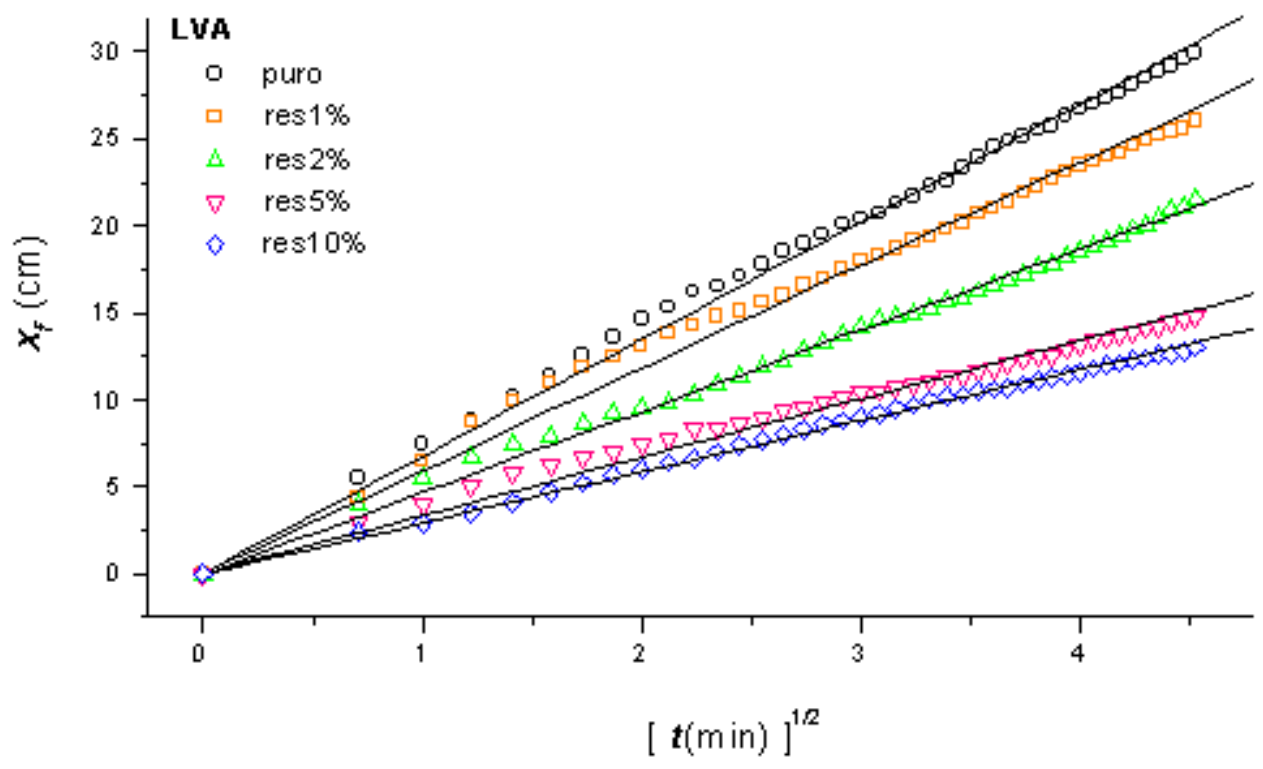

Figura 1: Curvas de $x_{f}$ em função de $t^{1 / 2}$ para o solo LVA e suas diversas concentrações de resíduo, com as respectivas linearizações das curvas.

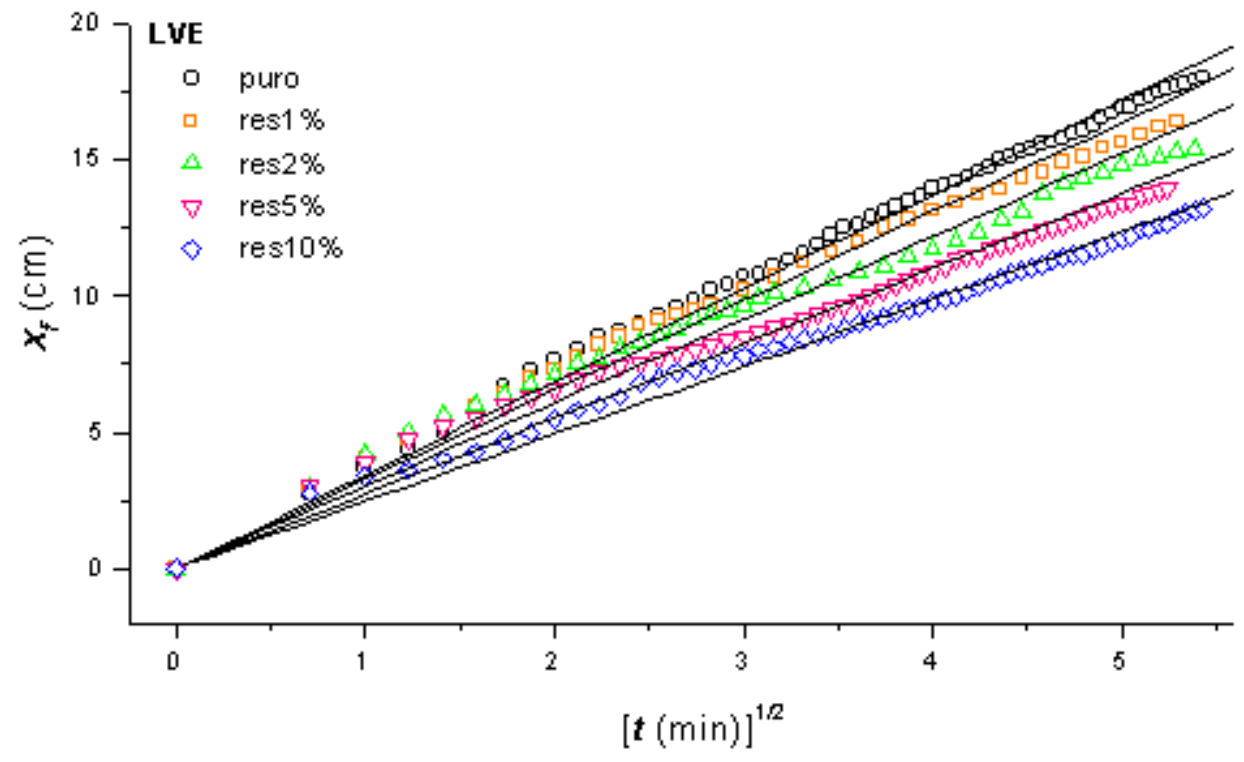

Figura 2: Curvas de $x_{f}$ em função de $t^{1 / 2}$ para o solo LVE e suas diversas concentrações de resíduo, com as respectivas linearizações das curvas. 


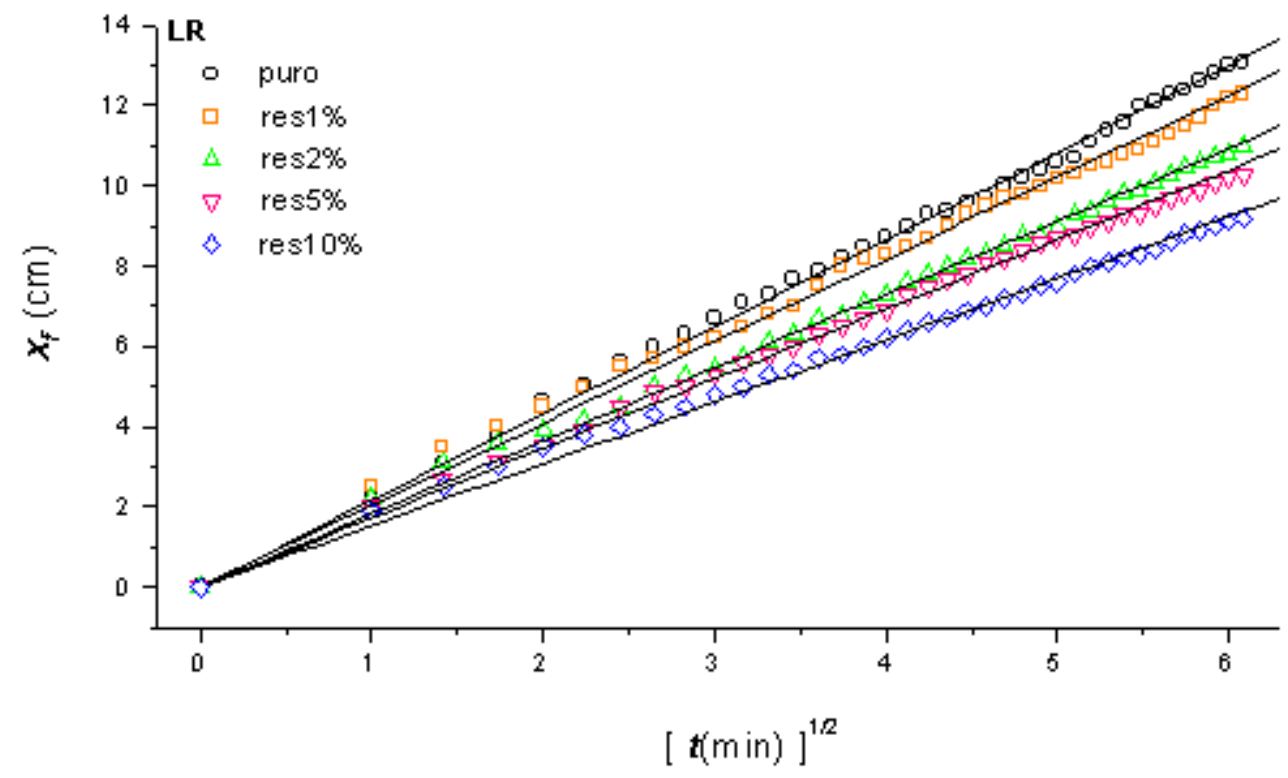

Figura 3: Curvas de $x_{f}$ em função de $t^{1 / 2}$ para o solo LR e suas diversas concentrações de resíduo, com as respectivas linearizações das curvas.

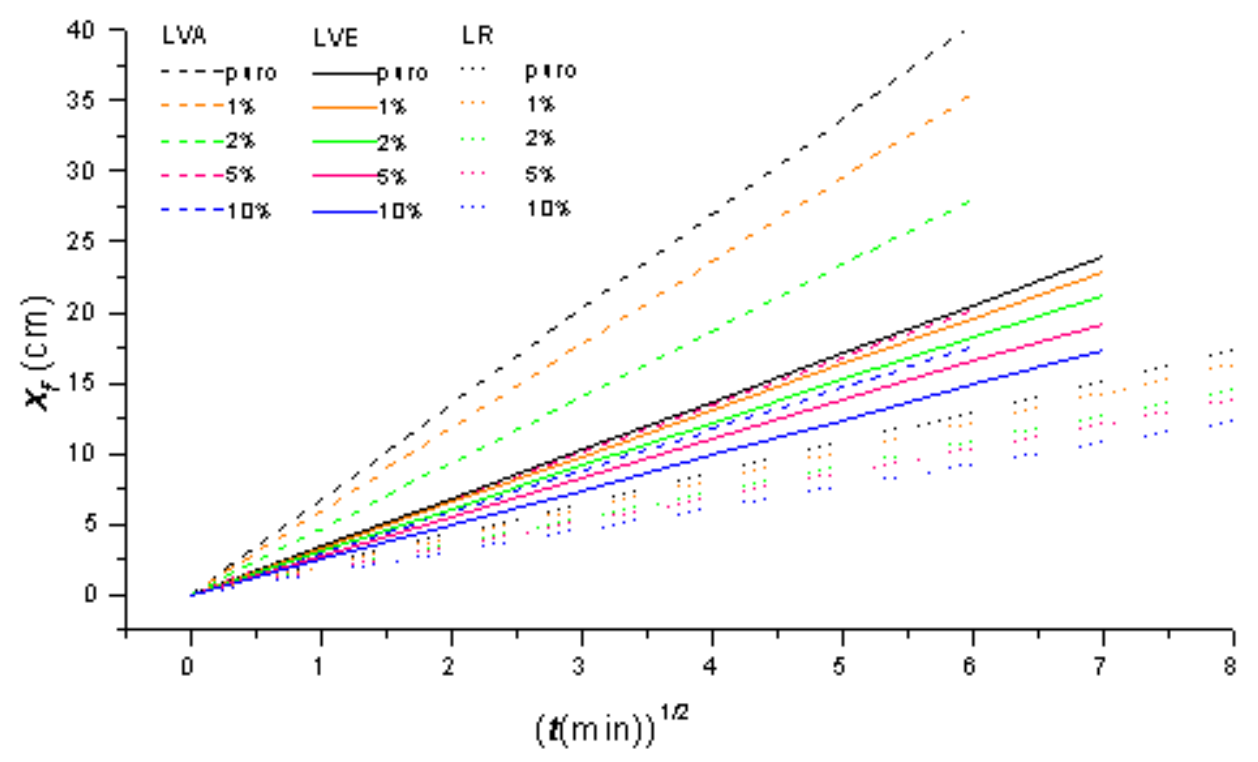

Figura 4: Curvas linearizadas de $x_{f}$ em função de $t^{1 / 2}$ para os solos LVA, LVE e LR e suas diversas concentrações de resíduo.

Tabela 3: Valores das umidades inicial ou residual $\left(\theta_{0}\right)$ e de saturação $\left(\theta_{1}\right)$ e dos 
parâmetros da regressão linear dos pontos $x_{\boldsymbol{f}}$ em função de $t^{1 / 2}$ para cada tipo de solo e suas concentrações.

\begin{tabular}{|c|c|c|c|c|c|c|}
\hline resíduo & $\begin{array}{c}\theta_{0} \\
\mathrm{~cm}^{3} / \mathrm{cm}^{3}\end{array}$ & $\begin{array}{c}\theta_{1} \\
\mathrm{~cm}^{3} / \mathrm{cm}^{3}\end{array}$ & $\begin{array}{c}\text { coeficiente } \\
\text { angular } \\
\text { m }_{\mathbf{i}}\end{array}$ & $\begin{array}{c}\text { erro } \\
\text { padrão }\end{array}$ & \begin{tabular}{|} 
coeficiente de \\
determinação \\
$\mathbf{R}$
\end{tabular} & $\mathbf{R}^{2}$ \\
\hline & & \multicolumn{5}{|c|}{ LVA } \\
\hline $\begin{array}{l}\text { solo } \\
\text { puro }\end{array}$ & 0,0075 & 0,4203 & 6,74 & 0,03 & 0,9990 & 0,9980 \\
\hline $1 \%$ & 0,0080 & 0,4216 & 5,91 & 0,04 & 0,9973 & 0,9947 \\
\hline $2 \%$ & 0,0102 & 0,4389 & 4,67 & 0,02 & 0,9986 & 0,9971 \\
\hline $5 \%$ & 0,0162 & 0,4573 & 3,36 & 0,02 & 0,9971 & 0,9943 \\
\hline $10 \%$ & 0,0366 & 0,4670 & 2,93 & 0,01 & 0,9988 & 0,9976 \\
\hline & & \multicolumn{5}{|c|}{ LVE } \\
\hline $\begin{array}{l}\text { solo } \\
\text { puro }\end{array}$ & 0,0346 & 0,5082 & 3,42 & 0,01 & 0,9984 & 0,9968 \\
\hline $1 \%$ & 0,0382 & 0,5010 & 3,27 & 0,03 & 0,9971 & 0,9943 \\
\hline $2 \%$ & 0,0391 & 0,4909 & 3,04 & 0,03 & 0,9951 & 0,9952 \\
\hline $5 \%$ & 0,0415 & 0,4753 & 2,75 & 0,02 & 0,9962 & 0,9924 \\
\hline $10 \%$ & 0,0615 & 0,4683 & 2,47 & 0,01 & 0,9980 & 0,9960 \\
\hline & & \multicolumn{5}{|c|}{ LR } \\
\hline $\begin{array}{l}\text { solo } \\
\text { puro }\end{array}$ & 0,0771 & 0,5013 & 2,16 & 0,01 & 0,9992 & 0,9984 \\
\hline $1 \%$ & 0,0788 & 0,5015 & 2,04 & 0,01 & 0,9987 & 0,9973 \\
\hline $2 \%$ & 0,0790 & 0,5042 & 1,82 & 0,01 & 0,9993 & 0,9985 \\
\hline $5 \%$ & 0,0846 & 0,5055 & 1,73 & 0,01 & 0,9992 & 0,9984 \\
\hline $10 \%$ & 0,0901 & 0,5147 & 1,54 & 0,01 & 0,9992 & 0,9985 \\
\hline
\end{tabular}

Observando-se os valores das umidades na Tabela 3, verifica-se que a 
umidade residual, ou seja, a umidade do solo seco ao ar é maior para os solos mais argilosos que para os mais arenosos e, além disso, cresce proporcionalmente à quantidade de resíduo acrescentada aos solos. A umidade de saturação também apresentou esse comportamento em relação aos solos puros; já com relação às misturas, apresentou um crescimento no LVA, um decrescimento no LVE, e uma igualdade no solo LR.

Esses resultados indicaram que o uso do resíduo, dentro dos limites estudados, alteraram os atributos físico-hídricos dos solos utilizados aumentando o tempo para o avanço da frente de molhamento e conseqüentemente o tempo de retenção de água.

\section{REFERÊNCIAS BIBLIOGRÁFICAS}

AGGELIDES, S.M., LONDRA, P.A. Effects of compost produced from town wastes and sewage sludge on the physical properties of loamy and a clay soil. Bioresource Technology, v. 71, p. 253-9, 2000.

ÁVILA, J.S., FIGUEIREDO, A.V.D., SAMPAIO, N.S. A turfa como condicionador de solos. in: ENCONTRO SOBRE ESCOAMENTO EM MEIOS POROSOS, 15 1988, Uberlândia. Anais. p.644-55, 1988.

BORGES, E.N., LOMBARDI-NETO, F. CORREAA, G.F., da COSTA, L.M. Misturas de gesso e matéria orgânica alterando atributos físicos de um latossolo com compactação simulada. Rev. Bras. Ci. Solo, v. 21. n.1, 1997.

FREIRE, W.J., MORETTI FILHO, J. Condicionadores químicos e seus efeitos sobre os limites de consistência do solo. Eng. Agríc., Botucatu, v.3, n.1, p. 17-22, 1979.

GALBIATTI, J.A., BENINCASA, M., LUCAS JUNIOR, J., LUI, J.J. Efeitos da incorporação de efluente de biodigestor sobre alguns parâmetros do sistema solo-água-planta em milho. Científica, São Paulo, v. 19, n. 2, p. 105-18, 1991.

GALBIATTI, J.A., LIBARDI, P.L., BENINCASA, M., GARCIA, A. Influência da incorporação de vermiculita expandida sobre alguns parâmetros hídricos de três solos. Científica, São Paulo, v. 20, n. 2, p. 379-89, 1992.

HICKMAN, J.S., WHITNEY, D.A. Soil conditioners. North Central Regional Extension Publication 295, USA, s.d.

NIMAH, M.N., RYAN, J. CHAUDHRY, M.A. Effect of synthetic conditioners on soil water retention, hydraulic conductivity, porosity, and aggregation. Soil Sci. Soc. Am. J., v. 47, p. 742-5, 1983. 
REICHARDT, K., LIBARDI, P.L., NIELSEN, D.R. Unsaturated hydraulic conductivity determination by scaling technique. Soil Sci., v. 120, n. 3, p. 165-8, 1975.

SALATI, E., REICHARDT, K., URQUIAGA C, S. Efeitos da adição de vermiculita na retenção e armazenamento de água por latossolos. Rev. Bras. Ci. Solo, v. 4. n.3, p. 125-31,1980. 